\title{
ERRATA
}

\section{ERRATUM: Luminescence-spectrum and strength properties of rhodamine 6G-doped silica gel films [Phys. of the Solid State 40, 427-431 (March 1998)]}

G. E. Malashkevich

Institute of Molecular and Atomic Physics, Academy of Sciences of Belarus, 220072 Minsk, Belarus

E. N. Poddenezny̆, I. M. Mil'nichenko, V. B. Prokopenko, and D. V. Dem'yanenko

F. Skorina Geomel State University, 256699 Gomel, Belarus

Fiz. Tverd. Tela (St. Petersburg) 40, 1574 (August 1998)

[S1063-7834(98)03708-3]

Figures to this article are as follows:
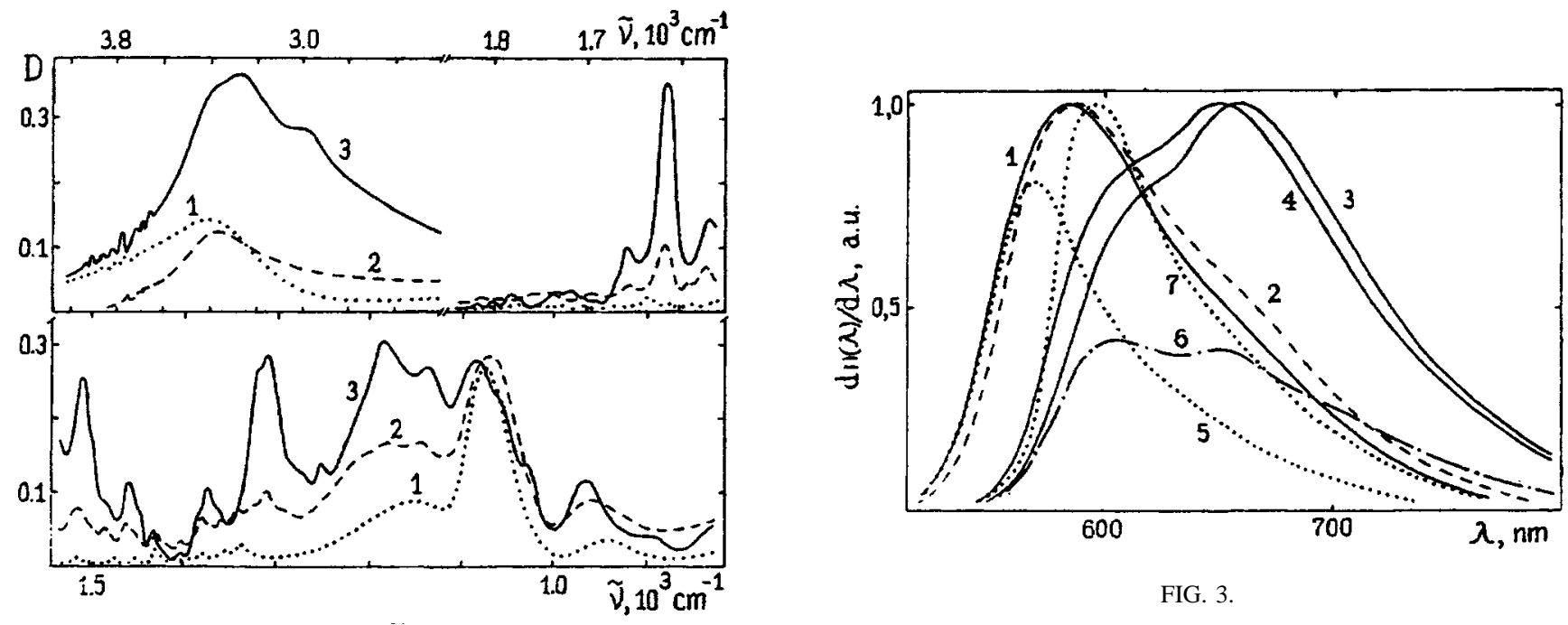

FIG. 3 .

FIG. 1.

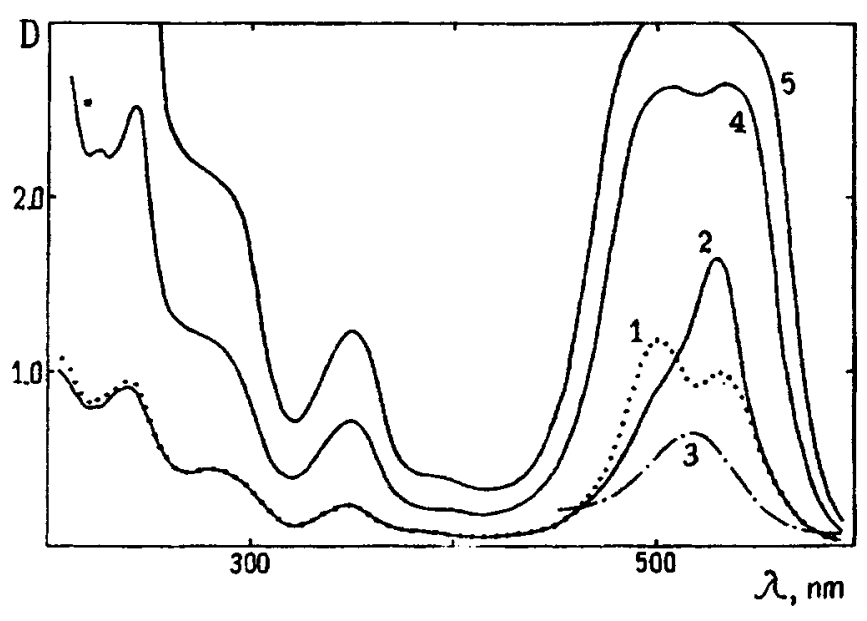

FIG. 2.

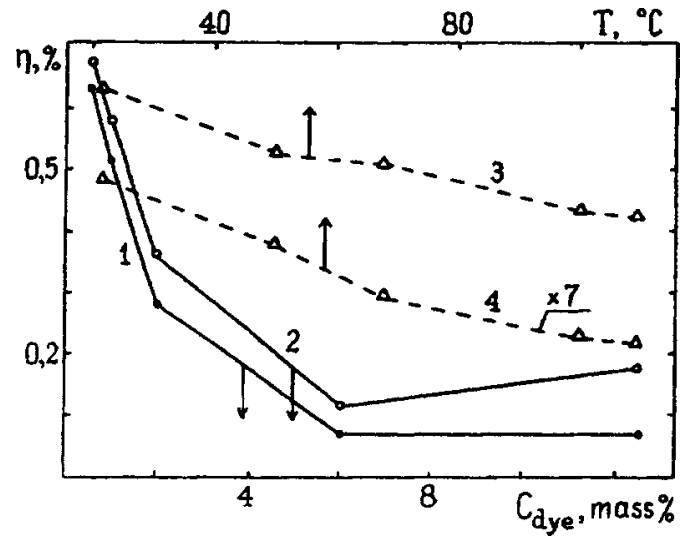

FIG. 4. 